\title{
Reelección y democracia: cambios en los valores de la población
}

\author{
Julia Isabel Flores \\ Omar Alejandre \\ Miguel Ángel García \\ Eliza Osorio Castro
}

\section{Sumario:}

I. Introducción

II. El principio de la no reelección

III. Actitudes y valores sobre la reelección

IV. La reelección en la Presidencia de la República

$\checkmark$. La reelección y el Poder Legislativo en México

VI. Senado de la República

VII. Cámara de Diputados

VIII. Reelección en otros niveles de gobierno

IX. Conclusiones

X. Bibliografía 


\section{Introducción}

La elección de las instituciones políticas es importante durante las transiciones a la democracia. En las democracias consolidadas estas instituciones están bien enraizadas y no se modifican con frecuencia. Los actores políticos han aprendido a acomodarse y a funcionar con dichas instituciones y de acuerdo a ellas es que diseñan sus estrategias.

Se ha señalado por autores como Linz $^{1}$ y como Mainwearing ${ }^{2}$ que el sistema presidencial ha demostrado ser menos capaz que el parlamentario para dar sustento a la democracia. En países como México, que experimentó una reciente transición a la democracia, se ha renovado el debate acerca de cuáles son las instituciones políticas que favorecen el desarrollo de un gobierno democrático, siendo la reelección una de las más debatidas.

Las percepciones de los mexicanos sobre el sistema político han sufrido transformaciones importantes en la última década. Uno de los cambios más destacados se manifiesta en la opinión sobre la no reelección, uno de los pilares fundamentales del sistema político mexicano.

En el imaginario social mexicano, la reelección se vincula a un régimen dictatorial y no con la democracia. El principio "Sufragio efectivo, no reelección" inicialmente uno de los baluartes del movimiento revolucionario mexicano de 1910 se convirtió en la base de la construcción y funcionamiento de un sistema político, que con algunos cambios, dura ya más de un siglo. La declinación de la ideología de la Revolución mexicana, por una parte, y las exigencias de construcción de un Estado democrático, por la otra, han llevado, particularmente después del año 2000, a la aceptación paulatina de la reelección como un instrumento útil para el mejor desempeño del gobierno y la instauración de una cultura de exigencia de rendición de cuentas.

En este trabajo se analizan y comparan los temas relativos a la opinión sobre la reelección en tres encuestas nacionales: La Encuesta Nacional de Reelección (IIJ, UNAM, 1998), La Primera Encuesta Na-

1 Linz, J. J., "Presidential or Paliamentary. Does it Makes a Difference?", en Linz, J. J. y Valenzuela, A. (eds.), Presidential or Parliamentary Democracy: Does it Make a Difference?, Baltimore, The johns Hopkins Univ. Press, 1998.

2 Mainwearing, Scott, "Presidentialism, Multipartism and Democracy: the Difficult Combination”, Comparative Political Studies, vol. 26, núm. 2, julio de 1993, pp. 198-228. 
cional de Cultura Constitucional (IIJ, UNAM, 2003) y la La Segunda Encuesta Nacional de Cultura Constitucional (IIJ, UNAM, 2010).

La opinión sobre la reelección ha ido cambiado en forma paulatina y sutil pero consistente, de su rotundo rechazo por la mayoría de la población, hacia una aprobación cada vez mayor. Así, la aprobación de la reelección del presidente de la República pasa de un 23\% en 1998 al $44.9 \%$ en 2010. Para los diputados federales los porcentajes cambian en términos similares: de un 23\% que en 1998 estuvo de acuerdo con la reelección de los diputados federales alcanza el $40 \%$ en 2010 . No obstante, todavía permanece profundamente arraigado en buena parte de la población el rechazo a la reelección.

\section{El principio de la no reelección}

Desde 1823 hasta 1911 la sucesión presidencial era un asunto que se resolvía por medio de la coacción y no por la vía de la elección, donde la posibilidad de elegir a un gobernante era un mero simulacro en pro de legitimar los previos actos de fuerza, o de influencia del presidente saliente para designar a alguno de sus incondicionales o, incluso, de su propia reelección. ${ }^{3}$

Desde el Supremo Poder Ejecutivo creado por el Congreso a la caída de Iturbide (1823) hasta Madero (presidente electo en 1911), México tuvo diecisiete gobiernos; de estos 17 gobiernos constitucionales, sólo cuatro, o tal vez cinco finalizaron al término de su periodo constitucional; los restantes fueron interrumpidos por derrocamiento, renuncia, licencia o muerte del gobernante respectivo. ${ }^{4}$

Fue hasta 1911, que en México, con la elección de Madero se inició por vez primera la celebración de elecciones pacíficas y libres que permitieron un tránsito hacia el cambio de gobierno y dieron paso a nuevos programas, en donde se hablaba de la expresión de la voluntad de las mayorías.

3 Muciño González, Juan Carlos, "No reelección legislativa: La responsabilidad política invertida", Revista del Instituto Electoral del Estado de México, Apuntes Electorales, núm. 18, 2004.

4 Emmerich, Gustavo, "Las elecciones en México, 1808-1911 ¿Sufragio Efectivo? ¿No - reelección?”, en González Casanova, Pablo, Las elecciones en México. Evolución y perspectivas, México, Siglo XXI, 1985. 
El movimiento revolucionario de 1910-1917 enarboló como bandera el "Sufragio efectivo y la no reelección" teniendo como marco el punto cuarto del Plan de San Luis Potosí, suscrito por Francisco I. Madero el 5 de octubre de 1910 consigna lo siguiente:

Además de la Constitución y leyes vigentes se declara ley suprema de la República, el principio de No reelección del Presidente y Vicepresidente de la República, Gobernadores de los Estados y Presidentes Municipales, mientras se hagan las reformas constitucionales respectivas.

Así, tiempo después, por medio de una ley suscrita el 27 de noviembre de 1910, el presidente Madero erigió en norma el citado principio que fue retomado en 1916 por Venustiano Carranza quien redactó un decreto que prohibía la reelección presidencial y establecía el nuevo periodo presidencial de cuatro años.

Después de ser convocado el Congreso Constituyente de 1916-1917 aprobó, con cambios muy menores, el dictamen del artículo 83 que contenía el principio de no reelección que le presentó la Comisión de Constitución elevando el que otrora fuera bandera del movimiento revolucionario al rango de canon constitucional.

En 1924, el general Obregón designó a Calles como su sucesor en la elección presidencial con el deseo de sustituirlo después de su periodo de cuatro años. En octubre de 1925, el Partido Agrarista propone la modificación constitucional que permitiría la reelección de Obregón para un periodo más, sin embargo, en un inicio no obtuvo un resultado positivo debido a la posición del Partido Laborista que se opone a dicha propuesta; pero para enero de 1926 el Congreso aprobó la reforma, y el 22 de enero de 1927, se público en el Diario Oficial. El segundo párrafo del artículo 83 quedo redactado así:

No podrá ser electo para el periodo inmediato. Pasando éste, podrá desempeñar nuevamente el cargo de presidente, sólo por un periodo más. Terminado el segundo periodo de ejercicio, quedará definitivamente incapacitado para ser electo y desempeñar el cargo de presidente en cualquier tiempo. ${ }^{5}$

5 Carpizo, Jorge, “El principio de No-Reelección”, en González Casanova, Pablo, Las elecciones en México..., cit. 
Nuevamente se dio una reforma al dispositivo 83 constitucional el 24 de enero de 1928 quedando de la siguiente forma:

El presidente entrará a ejercer su encargo el primero de Diciembre, durará en él cuatro años y nunca podrá ser reelecto.

Con respecto a este punto se presenta el dictamen de la Segunda Comisión (artículos 80 a 90 y 92) que señalan, en relación con la no reelección presidencial:

El período constitucional se deja para el Ejecutivo, siguiendo la tradición de la Constitución de 1857, en cuatro años; y se incorpora en el precepto respectivo la prohibición absoluta de que la persona que una vez ha ejercido el alto encargo de Presidente de la República vuelva a ejercerlo. ${ }^{6}$

Es hasta la muerte del general Obregón, el 29 de abril de 1933, que fue posible una nueva reforma al artículo constitucional antes aducido y que aparecerá publicado en el Diario Oficial de la Federación la cual subsiste hasta nuestros días: ${ }^{7}$

Artículo 83. El presidente entrará a ejercer su encargo el primero de diciembre y durara en él seis años. El ciudadano que haya desempeñado el cargo de presidente de la República, electo, en ningún caso y por ningún motivo podrá volver a desempeñar ese puesto.

En virtud de las modificaciones constitucionales de 1933 se dejó claro y firmemente en la Constitución el principio de no reelección para el cargo de presidente, sin embargo, no sucedió así con los demás cargos de elección popular. En un análisis realizado por el doctor Jorge Carpizo detalla al respecto que el principio de la no reelección en la Constitución de 1917 implica que se debe ser cauto y muy preciso con su interpretación, por lo que se delimita de la siguiente forma: ${ }^{8}$

${ }^{6}$ Diario de los Debates del Congreso Constituyente, cit. en Camargo, Pedro Pablo, Reelección presidencial y parlamentaria en América y México, México, UNAM, 1965, p 60.

7 Carpizo, Jorge, op. cit.

8 Idem. 
a) El presidente de la República y los gobernadores electos por el pueblo jamás pueden volver a ocupar ese cargo.

b) Los gobernadores interinos, provisionales o con cualquier denominación no pueden ser gobernadores para el periodo inmediato, pero después sí.

c) Los senadores y diputados federales no pueden ser reelectos para el periodo inmediato pero después sí.

d) Los diputados a las legislaturas locales no pueden ser reelectos para el periodo inmediato, pero después sí.

e) Los presidentes municipales, regidores, síndicos de los ayuntamientos electos por el pueblo no pueden ser reelectos para el periodo inmediato, pero después sí, y si desempeñan esos cargos por designación de alguna autoridad, entonces no pueden ser electos para el periodo inmediato.

f) Los senadores y diputados federales y locales suplentes pueden ser electos para el periodo inmediato siempre que no hubieren estado en ejercicio, pero los propietarios no pueden ser electos para el periodo inmediato con el carácter de suplentes.

A partir del análisis antes citado, podemos señalar que en cuanto a la reelección de los miembros del Poder Legislativo, no existe ninguna prohibición en la Constitución de 1917:

La Cámara de Diputados se compondrá de dos representantes de la nación, electos en su totalidad cada dos años por los ciudadanos mexicanos.

Y el artículo 58 señala que:

La Cámara de Senadores se renovará por mitad cada dos años.

En consecuencia, tanto senadores como diputados podían ser reelegidos indefinidamente. No obstante, el artículo 59 de la Constitución fue reformado en 1933, quedando de la siguiente forma:

Los senadores y diputados al Congreso de la Unión no podrán ser reelectos para el período inmediato. Los senadores y diputados suplentes podrán ser electos para el período inmediato con el carácter de propietarios, siempre que no hubieran estado en ejercicio; pero los senadores y diputados propietarios no podrán ser electos para el período inmediato con el carácter de suplentes. 
Dicha prohibición de reelección inmediata para diputados y senadores se amplió también al artículo 115 incluyendo a los diputados de las legislaturas de los estados.

Los cambios efectuados en 1933 resucitan el artículo 57 de la Constitución de Apatzingán de 1814, que tomado de la Constitución de Cádiz (1812) establecía el principio de la no reelección para los diputados. En todos los demás textos constitucionales del país se permitía la reelección para diputados y senadores.

Las reformas de 1933 tuvieron su origen en las resoluciones de la Convención extraordinaria del Partido Nacional Revolucionario reunida en Aguascalientes en octubre de 1932. El Congreso de la Unión fue convocado a sesiones extraordinarias el 2 de marzo de 1933 y el 29 del mismo mes y año se efectuó su promulgación, previo el cómputo de la aprobación dada por las legislaturas de los estados.

Las razones por las que se introdujeron cambios al artículo 59, son en palabras del doctor Antonio Martínez Báez las siguientes:

Fue una asamblea extraordinaria de un partido político con fuerza incontrastable, el órgano extralegal que sin consulta alguna de carácter democrático "dictó", bajo la pasión creada por los acontecimientos políticos de 1928 y de 1932 y bajo la influencia y aún la sombra de los generales Álvaro Obregón y Plutarco Elías Calles, las caprichosas e ilógicas reformas a la organización del Congreso Federal, olvidando tanto las doctrinas de la ciencia del derecho político, como la experiencia revelada en algunos períodos brillantes del parlamentarismo mexicano. ${ }^{9}$

Es nuevamente hasta 1964 en la representación de la XVLI Legislatura de la Cámara de Diputados cuando el tema de la reelección vuelve a saltar a tribuna, esta vez, el 13 de octubre, el Partido Popular Socialista presentó ante la Cámara un proyecto para restablecer la reelección indefinida de los diputados. ${ }^{10}$ Los diputados Enrique Ramírez y Miguel

9 Martínez Báez, Antonio, "Los diputados frente a la Constitución”, Excélsior, 8 de enero de 1965, p. 7, cit. por Camargo, Pedro Pablo, op. cit., p. 67.

10 El Partido Popular Socialista en su proyecto expuso como fundamento los antecedentes históricos y señalo que "las restricciones vigentes para la reelección de senadores y diputados son cuestiones de tiempo y no de principio; que los representantes del pueblo y de los Estados realizan mejor su función si adquieren los conocimientos necesarios para cumplir su tarea de legisladores y de vigilantes de la administración pública; que la reforma constitucional que estableció los diputados de partido, reconoce a todos los di- 
Osorio Marbán, integrantes de la Comisión de Puntos Constitucionales y miembros del PRI, se pronunciaron por un equilibrio del principio reelectivo, señalando que:

... en la Constitución coexisten los principios de no reelección y de reelección. El primero aplicable al Presidente de la República en forma absoluta, forma ya parte del derecho político mexicano, de los principios de la Revolución y de nuestra tradición histórica y se ha convertido en algo intocable. No hay posibilidad en la actual perspectiva histórica de que la no reelección aplicada al Presidente y a los gobernadores de elección popular sea siquiera debilitada. ${ }^{11}$

Es hasta 1965 que el artículo 59 fue motivo de intensos debates incluso en la opinión pública, a raíz de la presentación del proyecto presentado en 1964, el cual establecía la prohibición de la reelección de los senadores para un periodo inmediato y de los diputados para un tercer periodo consecutivo, de este modo se dio vigencia al actual dispositivo constitucional que sostiene:

Artículo 59. Los Senadores y Diputados al Congreso de la Unión no podrán ser reelectos para el periodo inmediato.

Los Senadores y Diputados Suplentes podrán ser electos para el período inmediato con el carácter de propietarios, siempre que no hubieren estado en ejercicio; pero los Senadores y Diputados propietarios no podrán ser electos para el período inmediato con el carácter de suplentes.

Al respecto promotores a favor de la reelección de legisladores al Congreso, en especial los miembros del Partido Acción Nacional, han sostenido que la reelección de los miembros del Congreso, que en México fue tradición constitucional iniciada en 1824, sólo fue rota en 1933

putados el carácter de representantes de los ciudadanos y el de representantes de sectores sociales con ideas e intereses qué defender y que en todo el mundo la reelección de los representantes del pueblo es ley y costumbre, porque los partidos políticos que los proponen saben quienes tienen la capacidad y experiencia para la tarea parlamentaria y por ello seleccionan a los más capaces y fieles a los principios y programas que sustentan". Paradójicamente Lombardo Toledano, uno de los oradores del Partido Popular Socialista y a nombre de su partido votó en contra de la iniciativa que su propio partido presentó. Véase Christlieb Ibarrola, Adolfo, Crónicas de la No-reelección, México, Partido Acción Nacional, 1965.

11 Ibidem, p. 42. 
para quebrantar al Poder Legislativo en beneficio del Ejecutivo, sin que las tendencias políticas de la Revolución siquiera se hubieran enfilado hacia la no reelección de diputados y senadores. Este quebranto no sólo va en contra de la institución del Congreso, sino también contra los hombres que lo integran, teniendo conocimiento de las prácticas políticas viciosas que dejan los cargos del Poder Legislativo casi a la disposición total del Ejecutivo.

En la realidad mexicana, sólo la reelección presidencial ha causado problemas políticos y ha justificado, con proyección histórica permanente, la no reelección como principio firme en la estructuración del Poder Ejecutivo y la estructura estatal. Y es natural. Sólo en el presidente de la República puede identificarse toda la autoridad y la fuerza de un poder, con la persona misma de quien lo ejerce. En cambio, ningún diputado en lo personal tiene autoridad como poder. Si acaso, en un Congreso que funcione debidamente, un diputado puede tener la autoridad moral y la fuerza política que quieran reconocerle sus compañeros de Cámara, su propio partido y los partidos adversarios. Pero ningún diputado, en el ejercicio legítimo de sus funciones, tiene capacidad legal, autoridad o fuerza políticas, para crear al país dificultades que no puedan encauzarse en el seno mismo de la Cámara. ${ }^{12}$

En la actualidad diversos debates en el mundo de la academia han señalado serias ventajas respecto a la reelección legislativa, las cuales se enfocan principalmente al fortalecimiento del Congreso, señalando que posibilitarían una verdadera división de poderes y la efectividad del sistema de pesos y contrapesos; mantendría a la representación política puesto que la posibilidad y expectativa de la reelección obliga a que el representante no se desvincule de sus representados ya que de lo contrario perdería el voto que lo sostendría en el puesto; establecería un mecanismo de rendición de cuentas, acompañado por su uso como método de premiación o castigo a través del voto; incentivaría y daría sentido a la participación; coadyuvaría a la formación de una cultura política democrática; llevaría a la carrera parlamentaria y a la especialización; otorgaría continuidad a los proyectos y elevaría su calidad, y favorecería la descentralización o una centralización menos intensa al interior de los partidos. Asimismo, estos mismos enfoques pro reeleccionistas señalan que un Congreso fuerte y representativo puede ser un instrumento eficaz en la solución de problemas. Ideal-

12 Ibidem, p. 53. 
mente un Congreso así implica acuerdos entre fuerzas políticas y lleva a la colaboración entre los poderes, lo que garantiza la gobernabilidad. La reelección puede no ser la solución a varios de los problemas pero sí puede ser un instrumento enteramente democrático y altamente democratizante. ${ }^{13}$

Cabe señalar, por otra parte, que el principio de la no reelección plasmado en la Constitución cuenta en la actualidad con el apoyo de dispositivos constitucionales que permiten preservar su cumplimiento, artículos como el 41 y el 99 en su conjunto prevén un soporte extra en el cuidado para la celebración de las elecciones mediante su regulación y resguardo de los principios y reglas de equidad democrática, además de incorporarse facultades jurisdiccionales al Tribunal Electoral federal que cuida y garantiza la legalidad y certeza de una elección.

Es de sabida cuenta, que a lo largo del tiempo, los diferentes estudios de opinión han puesto de relieve un desacuerdo manifiesto de la población a la reelección de las autoridades en sus diversos niveles. Los estudios recientes muestran que este desacuerdo comienza poco a poco a revertirse.

Los principios de "Sufragio efectivo y no reelección", poseen un alto valor simbólico entre la población, no sólo por la memoria histórica sobre el ejercicio del poder en el siglo pasado y como principios básicos de la ideología de la Revolución mexicana de 1910-1917 que funda el moderno Estado mexicano, sino que, en especial, el principio de la no reelección se ha percibido, en parte, como base de la estabilidad del régimen y ambos principios se perciben como elementos base para la construcción de la democracia en el país.

El desacuerdo con la reelección tendía a ser más acentuado en el caso de la Presidencia de la República y de los diputados federales y locales. En el caso de la Presidencia el principio de la no reelección ha sido uno de los fundamentos básicos del Estado mexicano posrevolucionario y por lo tanto tiene un valor simbólico para la población. En el caso de los diputados federales y locales el desacuerdo se relacionaría con las percepciones negativas que existen sobre ellos en la población, así como la lejanía y desconocimiento de la mayoría de la población acerca de sus funciones y desempeño. Las autoridades

13 López Rubí Calderón, José Ramón, "Reflexiones sobre el Poder Legislativo en el contexto del cambio político mexicano", Revista del Instituto Electoral del Estado de México, Apuntes Electorales, núm. 18, 2004, pp. 39 y 40. 
municipales son aquellas que guardan mayor cercanía con la población, por lo tanto existirán mayores niveles de información acerca de sus funciones y su desempeño. Se esperaría que se presente un cierto grado de acuerdo con la reelección de los presidentes municipales. Dichos grados de acuerdo se encontrarían fuertemente relacionados con factores como las percepciones sobre la experiencia de gobierno en los diversos municipios y las simpatías partidistas de la población.

\section{Actitudes y valores sobre la reelección}

Las preocupaciones sobre la perpetuidad presidencial y cómo mantener una estabilidad política en ausencia de regímenes dictatoriales son tan viejas como el mismo presidencialismo. ${ }^{14}$ Aunque la tendencia latinoamericana que ha prevalecido en los últimos años ha sido el reformar esta forma de restricción política y se ha hablado de un movimiento que se encamina a la permisión de la reelección, aún está muy lejos de ser uniforme, ${ }^{15}$ y como fuerte ejemplo de la idea del reeleccionismo dentro de la historia de América Latina, el caso de México no es la excepción.

En México la reelección en el imaginario social se vincula a un régimen dictatorial como un mecanismo que asegura su desaparición y no con la democracia. El principio "Sufragio efectivo y no reelección" ha sido uno de los baluartes del movimiento revolucionario mexicano de 1910 durante mucho tiempo y se ha constituido como parte importante en la construcción del nacionalismo para la población del país.

Por otra parte, al no existir una cultura de exigencia de rendición de cuentas en la mayoría de la población, la reelección pierde importancia como un instrumento útil a través del cual en primer lugar, se puede suscitar una mayor participación activa a través del voto ciudadano al percibir los votantes un incremento en las posibilidades de incidencia en las instituciones. ${ }^{16}$ En segundo, la consecuencia de una dinámica en que la premiación o el castigo de la labor de un funciona-

${ }^{14}$ Carey, John M., “The Reelection Debate in Latin America”, Latin American Politics and Society, vol. 45, núm. 1, primavera de 2003, p. 120.

15 Ibidem, p. 125.

16 Ibidem, p. 126. 
rio se mida, como señala Carey (2003), a partir de un contexto donde la capacidad de respuesta y responsabilidad a las necesidades sociales sirva de parámetro para una mayor calidad de la democracia.

No obstante lo anterior, actualmente la ideología de la Revolución mexicana que ha dado sustento al Estado mexicano parece declinar en algunos de sus contenidos y haber perdido su vigencia en el discurso para una parte de la población; sin embargo, se ha señalado que algunos de sus principios permanecen profundamente arraigados en el imaginario de la población sustentando un fuerte nacionalismo y la cuestión de la reelección es uno de ellos.

Por lo mismo, no es de extrañar que con respecto al principio del "Sufragio efectivo y no reelección", bandera del movimiento revolucionario mexicano de 1910-17, siga vigente para la población manifestándose en una fuerte negativa a la reelección en general. Sin embargo, no hay que dejar de lado que siempre ha sido la figura presidencial la que ha abanderado el principio de no reelección en nuestro país, es por ello que podría deducirse que la postura de los mexicanos con respecto a las figuras susceptibles de no reelegirse podría haber evolucionado de distinta forma.

En mayo de 1998 en la Encuesta Nacional de Reelección e Impartición de Justicia llevada a cabo por el Instituto de Investigaciones Jurídicas, UNAM, ${ }^{17}$ se exploró esta posibilidad, es decir, que si las actitudes negativas hacia la reelección se matizaban dependiendo de los niveles del gobierno. El resultado fue que al preguntar ¿qué tan de acuerdo o en desacuerdo estaría usted con que... pudieran reelegirse? La distribución de opinión acerca de la reelección para los diversos niveles de gobierno fue la siguiente: la mayoría de los entrevistados está en desacuerdo con el principio de reelección de los funcionarios en determinados puestos públicos, aunque en general el saldo que se arroja es que no aceptan la reelección más de la mitad de los encuestados (véase cuadro 1).

17 Encuesta Nacional de Reelección e Impartición de Justicia, Instituto de Investigaciones Jurídicas, UNAM, mayo de 1998. Encuesta nacional en vivienda de 1200 casos a personas de 18 años o más. 95\% de confianza +-3 puntos de margen de error. 


\section{Cuadro 1}

En México no hay reelección, es decir que los funcionarios públicos no pueden volver a ser electos para el mismo puesto. ¿Qué tan de acuerdo o en desacuerdo estaría usted con que pudiera reelegirse:

(Porcentajes)

\begin{tabular}{|c|c|c|c|c|c|c|c|c|c|c|c|c|c|c|c|}
\hline \multicolumn{6}{|c|}{$\begin{array}{l}\text { Encuesta Nacional de Reelección e } \\
\text { Impartición de Justicia* } \\
1998\end{array}$} & \multicolumn{5}{|c|}{$\begin{array}{c}\text { Primera Encuesta Nacional de Cultura } \\
\text { Constitucional }{ }^{* *} \\
2003\end{array}$} & \multicolumn{5}{|c|}{$\begin{array}{l}\text { Segunda Encuesta Nacional de Cultura } \\
\text { Constitucional }{ }^{* * *} \\
2011\end{array}$} \\
\hline & Acuerdo & $\begin{array}{l}\text { Acuerdo } \\
\text { en parte }\end{array}$ & $\begin{array}{l}\text { Desacuerdo } \\
\text { en parte }\end{array}$ & Desacuerdo & $\begin{array}{l}\mathrm{NS} / \\
\mathrm{NC}\end{array}$ & Acuerdo & $\begin{array}{l}\text { Acuerdo } \\
\text { en parte }\end{array}$ & Desacuerdo & Otra & $\begin{array}{l}\mathrm{NS} / \\
\mathrm{NC}\end{array}$ & Acuerdo & $\begin{array}{l}\text { Acuerdo } \\
\text { en parte }\end{array}$ & Desacuerdo & Otra & $\begin{array}{l}\mathrm{NS} / \\
\mathrm{NC}\end{array}$ \\
\hline Presidente & $17 \%$ & $6 \%$ & $2 \%$ & $69 \%$ & $6 \%$ & $19.2 \%$ & $9.4 \%$ & $68.8 \%$ & $0.5 \%$ & $2.1 \%$ & $24.5 \%$ & $20.4 \%$ & $52.7 \%$ & $0.5 \%$ & $2.0 \%$ \\
\hline $\begin{array}{l}\text { Gobernador } \\
\text { (jefe de } \\
\text { gobierno D.F.) }\end{array}$ & $20 \%$ & $9 \%$ & $2 \%$ & $66 \%$ & $3 \%$ & $16.9 \%$ & $7.8 \%$ & $72.5 \%$ & $0.4 \%$ & $2.5 \%$ & $15.6 \%$ & $20.8 \%$ & $60.2 \%$ & $0.7 \%$ & $2.7 \%$ \\
\hline $\begin{array}{l}\text { Diputados } \\
\text { federales }\end{array}$ & $15 \%$ & $8 \%$ & $2 \%$ & $70 \%$ & $5 \%$ & $13.8 \%$ & $9.8 \%$ & $73.5 \%$ & $0.5 \%$ & $2.4 \%$ & $18.0 \%$ & $22.0 \%$ & $57.1 \%$ & $0.6 \%$ & $2.3 \%$ \\
\hline Senadores & & & & & & $14.6 \%$ & $8.4 \%$ & $74.5 \%$ & $0.5 \%$ & $2.1 \%$ & $16.3 \%$ & $20.7 \%$ & $59.7 \%$ & $0.7 \%$ & $2.5 \%$ \\
\hline $\begin{array}{l}\text { Presidentes } \\
\text { municipales } \\
\text { (jefes de } \\
\text { delegación) }\end{array}$ & $20 \%$ & $10 \%$ & $2 \%$ & $65 \%$ & $3 \%$ & $15.0 \%$ & $8.6 \%$ & $73.0 \%$ & $0.6 \%$ & $2.8 \%$ & $17.2 \%$ & $18.6 \%$ & $59.5 \%$ & $0.8 \%$ & $3.9 \%$ \\
\hline
\end{tabular}

Fuente:

* México, UNAM, Instituto de Investigaciones Jurídicas, mayo de 1998. Encuesta nacional en vivienda de 1200 casos a personas de 18 años y más.

** México, UNAM, Instituto de Investigaciones Jurídicas, 2003. Encuesta nacional en vivienda de 1794 casos a personas de 15 años y más.

*** México, UNAM, Instituto de Investigaciones Jurídicas, mayo de 2011. Encuesta nacional en vivienda de 2208 casos a personas de 15 años y más 


\section{La reelección en la Presidencia de la República}

Los resultados del cuadro 1 muestran que la figura presidencial sigue siendo un símbolo importante vinculado al principio de la no reelección. Como se observa en la gráfica 1 en 1998 las opiniones que están de acuerdo (o en parte) con la reelección del presidente de la República fue de sólo un $23 \%$, porcentaje que respalda, como ya se ha mencionado, el alto valor simbólico que la población otorga a la Presidencia de la República.

$\mathrm{Al}$ percibirse la figura presidencial como un elemento central del sistema político, la no reelección se valora como un factor que asegura la continuidad del sistema, a la vez que su reproducción, ya que permite la circulación de los grupos en el poder. La no reelección es valorada entonces, como una fuente que otorga estabilidad y legitimidad al sistema político. Adicionalmente, las percepciones negativas de la situación económica y política del país y la experiencia de las crisis económicas registradas durante esos años, contribuyeron al desacuerdo con la reelección del presidente de la República.

\section{Gráfica 1. Reelección presidencial}

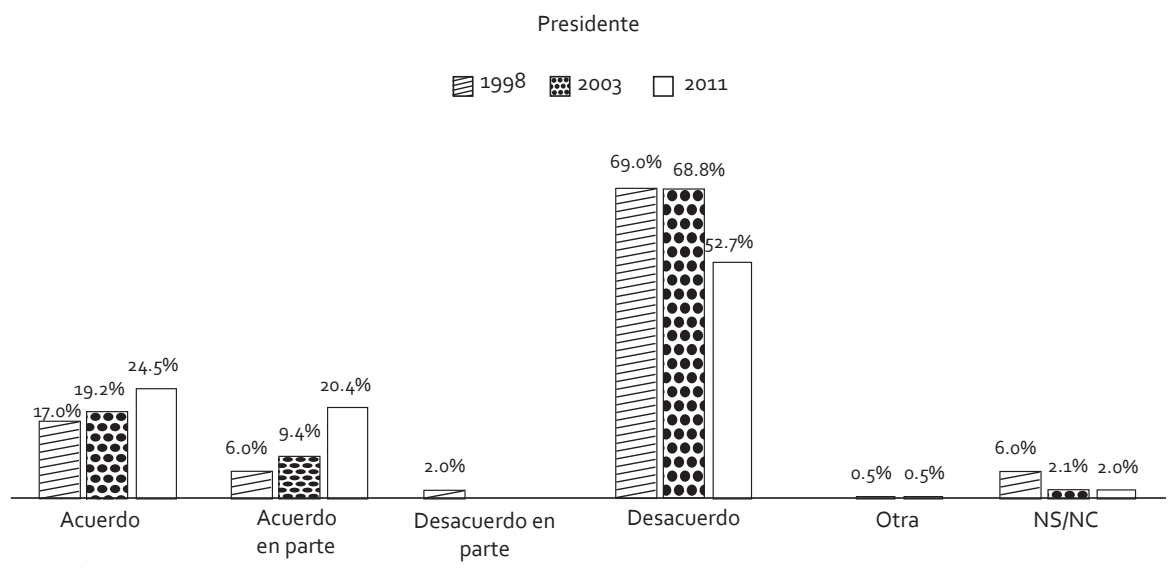

Fuente:

1. Encuesta Nacional de Reelección e Impartición de Justicia, cit.

2. Encuesta Nacional de Cultura Constitucional, cit.

3. Segunda Encuesta Nacional de Cultura Constitucional, cit. 
La situación que anteriormente se señala en lo que refiere a la aceptación dentro de la población de la posible reelección presidencial cambia en poca proporción en los años subsecuentes, como puede apreciarse en los resultados que arroja la Encuesta Cultura de la Constitución en México levantada en 2003. ${ }^{18}$ Aquí las personas que señalan estar de acuerdo (o en parte) con la reelección del presidente de la República aumenta ligeramente a $28.6 \%$, pero, al igual que en 1998 , aún se registran altos grados de desacuerdo que abarcan a siete de cada diez entrevistados (véase gráfica 1).

Para el momento en que es efectuada la réplica de la Encuesta Cultura de la Constitución en México en $2011^{19}$ el panorama cambia de manera importante con respecto a este tema, la opinión se encuentra ahora dividida creciendo las posturas de los entrevistados que están de acuerdo (o en parte) con la reelección del presidente en un 45\%, mientras que el desacuerdo disminuye a poco más de la mitad de los entrevistados (véase gráfica 1). En este caso sobresalen los jóvenes, las personas con mayor ingreso y los militantes del PAN como los que más están de acuerdo con que exista reelección del presidente de la República.

\section{La reelección y el Poder Legislativo en México}

Aunque, en general, en Latinoamérica las prohibiciones sobre la reelección legislativa cada vez son más raras México es uno de los que aún mantiene ciertas prohibiciones constitucionales al establecer la prohibición de reelección consecutiva de sus legisladores. ${ }^{20}$

En un primer acercamiento la discusión de la postura que prevalece acerca de la reelección legislativa tiene un carácter diferente al

18 Encuesta Cultura de la Constitución en México, México, UNAM, Instituto de Investigaciones Jurídicas, 2003. Encuesta nacional de 1794 casos en vivienda a personas de 15 años y más levantada en Enero de 2003.

19 Segunda Encuesta Nacional de Cultura Constitucional, México, UNAM, Instituto de Investigaciones Jurídicas, 2011. Encuesta nacional de 2208 casos en vivienda a personas de 15 años y más levantada en mayo de 2011.

20 En México se han suscitado discusiones sobre el tema para la abolición de dichas restricciones, sin embargo no han sido aceptadas las propuestas. Carey, John M., "The Reelection Debate in Latin America", op. cit., p. 130 
explorado en líneas previas donde la figura presidencial se enfrenta a un rotundo $\mathrm{NO}$ en lo que respecta a la cuestión de la reelección hablando en términos constitucionales. En contraste, la discusión en el caso de la reelección legislativa es por la prohibición a la continuidad en el puesto de forma inmediata para el legislador. ${ }^{21}$ Aún así el rechazo que existe hacia la figura de la reelección más que hacia el beneficio o perjuicio de los legisladores permanece presente en la opinión de los mexicanos.

\section{Senado de la República}

En el caso de los senadores de la República en la Encuesta realizada en 2003 se inquirió sobre la reelección, y los niveles alcanzados se observan similares a los obtenidos para los diputados federales. De la población entrevistada en siete de cada diez no está de acuerdo con que se modifiquen las estipulaciones constitucionales para permitir la continuidad en el puesto.

\section{Gráfica 2. Reelección legislativa. Senadores}

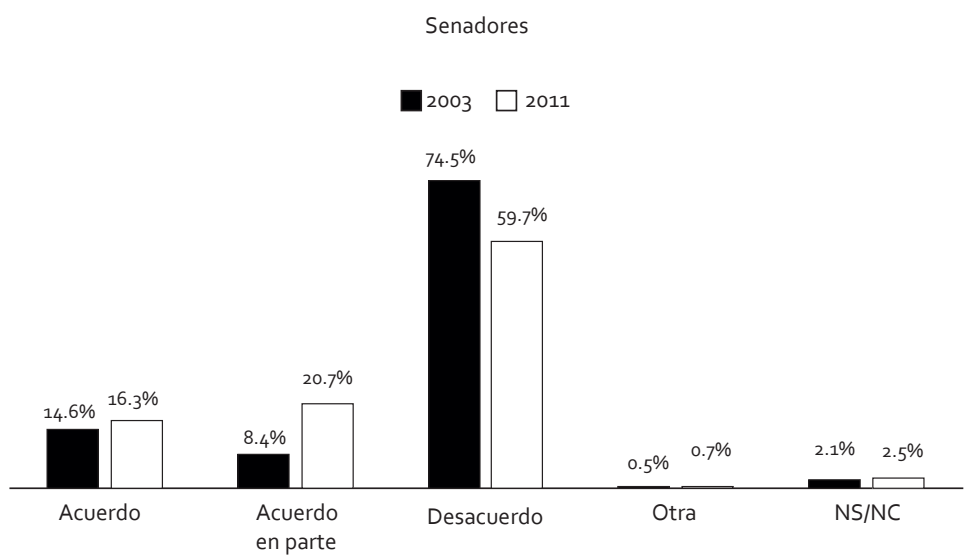

Fuente:

1. Encuesta Nacional de Cultura Constitucional, cit.

2. Segunda Encuesta Nacional de Cultura Constitucional, cit.

${ }^{21}$ Carbonell, Miguel, "Hacia un Congreso profesional: la no reelección legislativa en México”, La Cámara de Diputados en México, México, Miguel Ángel Porrúa-Cámara de Diputados, 2000, p. 107. 
El panorama observado en 2003 cambia para 2011 en la Segunda Encuesta sobre Cultura Constitucional, donde las respuestas de la población sobre la reelección de senadores disminuye en cuanto a la negativa de un $74.5 \%$ a un $59.7 \%$ y se incrementa en el acuerdo (o en parte) entre los entrevistados con un $23 \%$ a un $37 \%$ de aceptación (véase gráfica 2).

\section{Cámara de Diputados}

En el caso de la reelección de los diputados en los resultados de 1998 se registró la postura en desacuerdo más alta de todos los niveles de gobierno: $72 \%$. Este contexto se explica por motivos distintos a los que se presentan en el caso del presidente de la República (véase gráfica 3).

Entre ellos se encuentra: la supeditación del Legislativo al Ejecutivo, que caracterizó durante buena parte del siglo XX la práctica del ejercicio del poder en México. La relación lejana con los representados y la falta de arraigo. La poca visibilidad de su labor, aunada al desconocimiento de sus funciones; así como la carencia de un oficio y tradición parlamentarias que contribuyeron, entre otros factores, a consolidar y a sedimentar una imagen negativa de los diputados, que no sería ni será fácil de revertir en la opinión de los mexicanos, por lo menos, en el corto plazo.

Gráfica 3. Reelección legislativa. Diputados federales

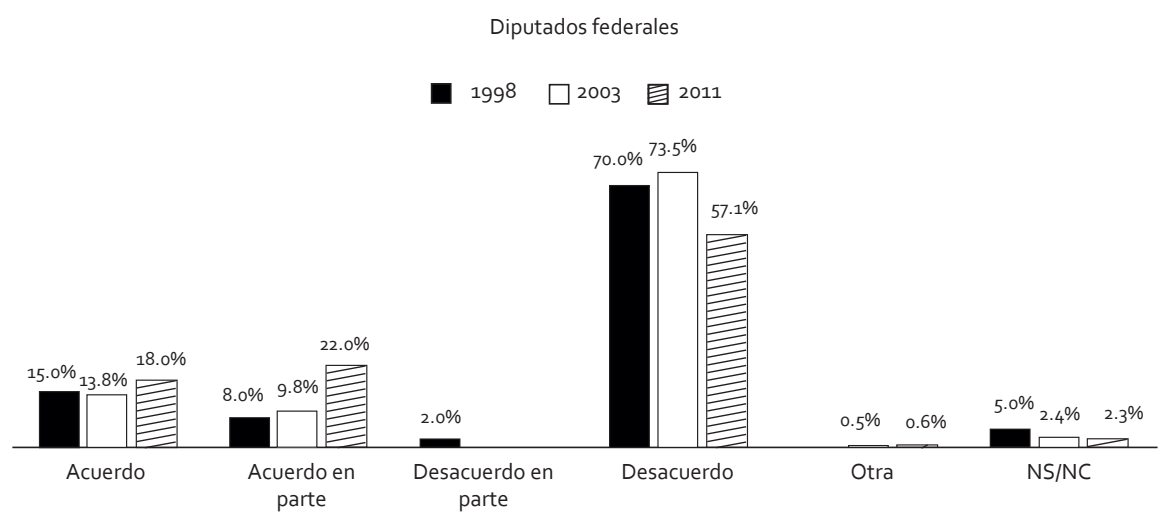

Fuente: 1. Encuesta Nacional de Reelección e Impartición de Justicia, cit.

2. Encuesta Nacional de Cultura Constitucional, cit.

3. Segunda Encuesta Nacional de Cultura Constitucional, cit. 
El argumento previo se ve respaldado por los resultados arrojados en la Encuesta de 2003 ya que al indagar con la población entrevistada sobre la reelección legislativa en este caso de los diputados federales, la postura de acuerdo obtuvo un 23\% manteniéndose en los mismos niveles que en 1998. A este respecto la Encuesta de 2011 arroja también un cambio importante en las posturas de los mexicanos con respecto a la reelección de diputados al incrementarse hasta un $40 \%$ la población que estuvo de acuerdo (o en parte) con esta situación.

A este respecto cabe mencionar también que sobresalen por su aprobación de la reelección los varones, jóvenes, las personas con niveles altos de escolaridad e ingreso y quienes se identificaron más con el PRD y el PAN.

Por otro lado, con respecto a la reelección legislativa (en este caso diputados federales) en la Segunda Encuesta Nacional de Cultura Constitucional se plantearon preguntas para recoger las percepciones del público sobre la reelección de los diputados federales en relación con su desempeño. En torno a la idea de que la reelección constituiría un acicate para el mejoramiento de su función.

A la pregunta, ¿Con cuál de las siguientes frases está usted más de acuerdo...? "Si en México hubiera reelección los diputados harían mejor su trabajo para que la gente los reelija" o "Los diputados seguirían trabajando igual que hasta ahora". La opinión se muestra dividida: un $42 \%$ considera que los diputados harían un mejor trabajo, particularmente los jóvenes, las personas con más altos niveles de escolaridad y quienes no cuentan con ninguna, quienes habitan en ciudades medias, las personas que se identifican con el PAN y quienes habitan en el sur del país. En contraste, los que piensan que los diputados seguirían trabajando igual que ahora son los varones, los adultos de 65 años o más, quienes tienen menores niveles de escolaridad, las personas que se identifican con el PAN y quienes habitan en las regiones centro y centro-occidente del país (véase gráfica 4). 


\section{Gráfica 4. Reelección legislativa (diputados federales)}

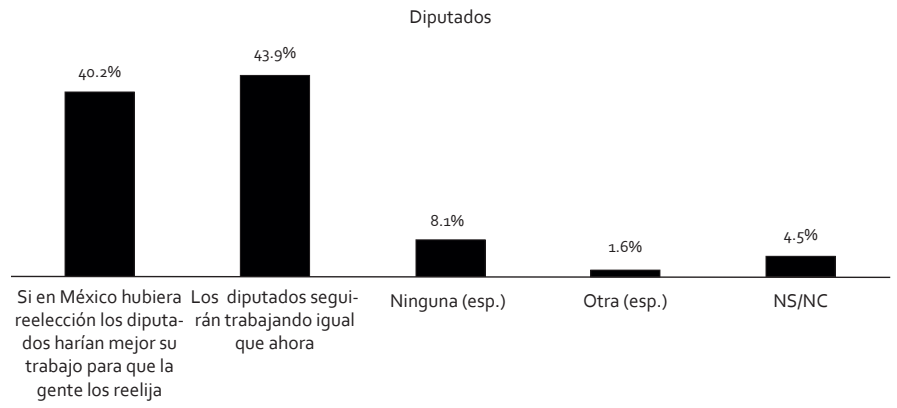

Fuente: Segunda Encuesta Nacional de Cultura Constitucional, cit.

A partir de las posturas en la pregunta anterior y con el propósito de conocer, en caso de existir la reelección legislativa, la disposición de los entrevistados de premiar o castigar con su voto el desempeño de los diputados se planteó la pregunta: Si hubiera reelección en México y su diputado hubiera hecho un buen trabajo, ¿Votaría Ud. por él otra vez? Al respecto cuatro de cada diez entrevistados señalaron que votarían de nuevo por ese diputado, entre ellos se encuentran las personas con mayores niveles de escolaridad, quienes se identifican con el PAN y con el PRI, quienes habitan en las grandes ciudades y en el norte del país. En contraste la población que señaló que preferiría votar por otra persona fue un poco más de uno de cada cuatro entrevistados, por otro lado, menos de uno de cada diez señalaron que preferirían no votar (véase gráfica 5).

\section{Gráfica 5. Reelección legislativa (voto ciudadano)}

Diputados

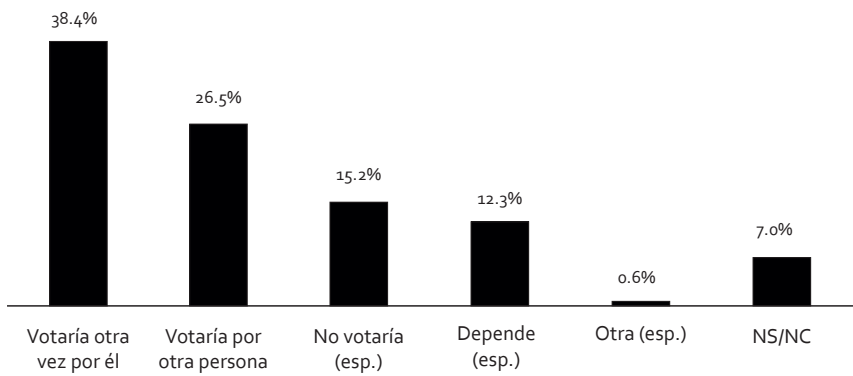

Fuente: Segunda Encuesta Nacional de Cultura Constitucional, cit. 


\section{Reelección en otros niveles de gobierno}

La cuestión de la reelección es un tema que atraviesa varios niveles del aparato estatal en nuestro país. En este caso, ¿las prohibiciones sobre la elección a las otras oficinas reflejan aquellas existentes sobre la Presidencia? La respuesta en el caso de los gobernadores, generalmente es sí, para otros no. ${ }^{22}$

Los gobernadores y los presidentes municipales se encuentran entre las autoridades más cercanas a la población. Las personas conocen sus funciones, pueden acercarse a ellos y evaluar el resultado de su trabajo con mayor facilidad que a otras autoridades; de allí que en 1998 existía un menor grado de desacuerdo - que aún así, alcanzó cifras muy altas- hacia su reelección.

Gráfica 6. Reelección de gobernador (jefe de gobierno D.F.)

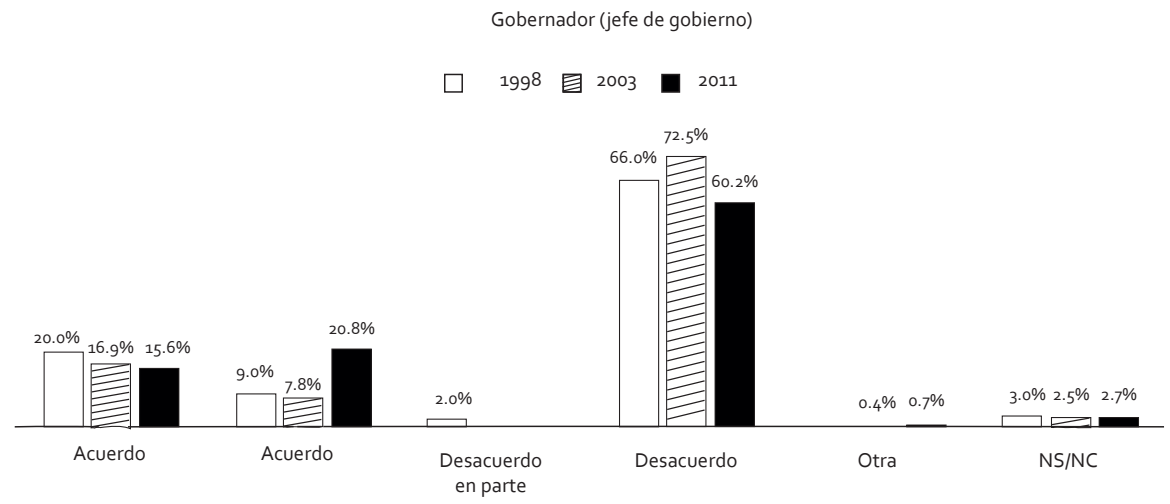

Fuente: 1. Encuesta Nacional de Reelección e Impartición de Justicia, cit.

2. Encuesta Nacional de Cultura Constitucional, cit.

3. Segunda Encuesta Nacional de Cultura Constitucional, cit.

Cuando las posiciones son designadas por elección popular, las restricciones sobre los gobernadores son comunes, y en el caso de México esas prohibiciones se materializan constitucional (artículo 116) y paralelamente a las presidenciales. Por ello no es de extrañar que en 1998 sólo un $29 \%$ estuviera de acuerdo con que el gobernador de un estado pudiera ser reelecto. No obstante, las tendencias observadas

${ }^{22}$ Carey, John M., “The Reelection Debate in Latin America”, op. cit., p. 129 
con respecto a otros niveles en cuanto al nivel de aceptación donde el acuerdo tiende a incrementarse, de 1998 a 2003 disminuye el acuerdo con la reelección de los gobernadores de los estados y de los presidentes municipales (véase gráfica 6).

\section{Gráfica 7. Reelección de presidentes municipales (jefes de Delegación)}

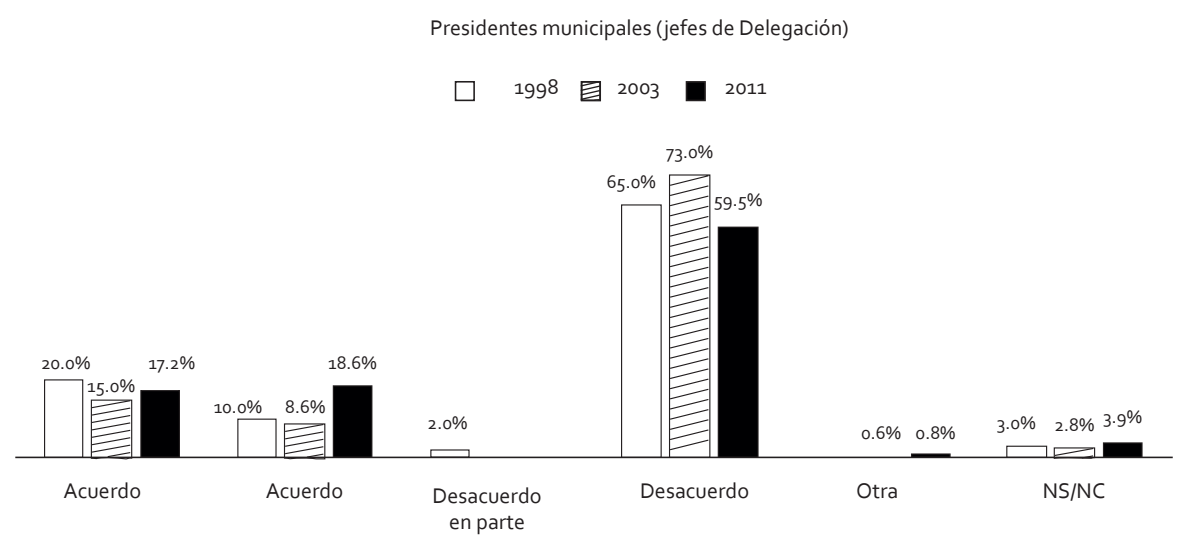

Fuente: 1. Encuesta Nacional de Reelección e Impartición de Justicia, cit.

2. Encuesta Nacional de Cultura Constitucional, cit.

3. Segunda Encuesta Nacional de Cultura Constitucional, cit.

Por otro lado, de todos los niveles de gobierno estudiados en 1998, la posibilidad a favor de la reelección de los presidentes municipales fue la mayor, ligeramente superior a la de los gobernadores: el grado de acuerdo alcanzó un 30\%. El municipio es la autoridad con más arraigo y una sólida tradición de gobierno en México desde la colonia, hasta nuestros días. Su autoridad es altamente visible y la más cercana a la población.

\section{Conclusiones}

La cultura política de los mexicanos está cambiando. Surgen nuevas formas de actuar en el terreno de lo público que antes no se consideraban como políticas. No obstante, no se ha resuelto aún la manera en que han de articularse con las normas y prácticas tradicionales. El 
encuentro y el desfase de los problemas y las soluciones de ayer y de hoy originan las distintas apreciaciones sobre la política en México y parte de este mosaico es el tema de la reelección.

Aunque en la sociedad comienza a crecer paulatinamente y a expresarse una corriente de opinión en favor de la reelección, que como ya se observó en líneas previas presenta una tendencia a aumentar y está presente ya en las generaciones jóvenes, así como en los estratos altos de escolaridad e ingreso; todavía no es mayoritaria estando vinculada a factores históricos, de legitimidad y credibilidad de los actores políticos, así como a la experiencia de los ciudadanos y las percepciones existentes sobre la representación y el ejercicio del poder.

Pero el saldo de los estudios explorados nos deja claro que existe una constante en la percepción de la importancia de mantener limitada y, en su caso, prohibida la reelección, es importante y preferible aunque los buenos gobernantes no tengan otra oportunidad, la percepción de que es mala para el país y eso aplica a todos los niveles del aparato estatal.

Es claro que van emergiendo discursos democráticos y en un proceso sutil, las prácticas y símbolos tradicionales se modifican para adecuarse a los nuevos tiempos. Sin embargo, esas prácticas y esos símbolos constituyen el contexto en el que se juzgarán los cambios.

\section{Bibliografía}

Carbonell, Miguel, "Hacia un Congreso Profesional, la no reelección legislativa en México", La Cámara de Diputados en México, México, Miguel Ángel Porrúa-Cámara de Diputados, 2000.

CArey, John M., "The Reelection Debate in Latin America”, Latin American Politics and Society, vol. 45, núm. 1, primavera de 2003.

CARPIzo, Jorge, "El principio de No-Reelección", en González CASAnova, Pablo, Las elecciones en México. Evolución y perspectivas, México, Siglo XXI, 1985.

Christlieb Ibarrola, Adolfo, Crónicas de la No - reelección, México, Partido Acción Nacional, 1965.

Diario de los debates del Congreso Constituyente, cit. en CAmargo, Pedro Pablo, Reelección presidencial y parlamentaria en América y México, México, UNAM, 1965. 
Emmerich, Gustavo, "Las elecciones en México, 1808-1911 ¿Sufragio Efectivo? ¿No - reelección?”, en González Casanova, Pablo, Las elecciones en México. Evolución y perspectivas, México, Siglo XXI, 1985.

Linz, J. J., "Presidential or Paliamentary. Does it Makes a Difference?", en Linz, J. J. y Valenzuela, A. (eds.), Presidential or Parliamentary Democracy: Does it Make a Difference?, Baltimore, The johns Hopkins Univ. Press, 1998.

López Rubí Calderón, José Ramón, "Reflexiones sobre el Poder Legislativo en el contexto del cambio político mexicano", Revista del Instituto Electoral del Estado de México, Apuntes Electorales, núm. 18, 2004.

Mainwearing, Scott, "Presidentialism, Multipartism and Democracy: the Difficult Combination", Comparative Political Studies, vol. 26, núm. 2, julio de 1993.

MuciÑo González, Juan Carlos, "No reelección legislativa: La responsabilidad política invertida", Revista del Instituto Electoral del Estado de México, Apuntes Electorales, núm. 18, 2004.

\section{Encuestas}

Encuesta Nacional de Reelección e Impartición de Justicia, México, UNAM, Instituto de Investigaciones Jurídicas, mayo de 1998.

Encuesta Nacional de Cultura Constitucional, México, UNAM, Instituto de Investigaciones Jurídicas, 2003.

Segunda Encuesta Nacional de Cultura Constitucional, México, UNAM, Instituto de Investigaciones Jurídicas, mayo de 2011.

\section{Legislación}

Constitución Política de los Estados Unidos Mexicanos. 